\title{
Use of $l a c Z$ Gene Fusions to Determine the Dependence Pattern of the Sporulation Gene spoIID in spo Mutants of Bacillus subtilis
}

\author{
By SANDRA CLARKE, * ISABEL LOPEZ-DIAZ† AND \\ JOEL MANDELSTAM \\ Microbiology Unit, Department of Biochemistry, University of Oxford, South Parks Road, \\ Oxford $O X I 3 Q U, U K$
}

(Received 11 March 1986; revised 26 May 1986)

\begin{abstract}
The spoIID gene, which is involved in Bacillus subtilis sporulation, was fused to the $\beta$ galactosidase gene, lac $Z$, of Escherichia coli so that the expression of $\beta$-galactosidase would be under the control of the spoIID locus. When the fused product was inserted into the $B$. subtilis chromosome, production of $\beta$-galactosidase indicated that the spoIID gene was expressed $1.5 \mathrm{~h}$ after the start of sporulation. When the spoIID : :lac $Z$ fusion was inserted into the chromosome of sporulation mutants, all strains carrying spoO lesions and those with mutations in spoIIA, spoIIE and spoIIG loci failed to make $\beta$-galactosidase. The proposed provisional order of expression of operons governing stage II is spoIIA $\rightarrow[$ spoIIG, spoIIE $] \rightarrow[$ spoIID, spoIIB, spoIIF $]$.
\end{abstract}

\section{INTRODUCTION}

The initiation of sporulation in Bacillus subtilis is morphologically characterized by the deposition of an asymmetric septum. This is conventionally called stage II of the process, which in B. subtilis, is controlled by six known genetic loci: spoIIA, spoIIB, spoIID, spoIIE, spoIIF and spoIIG. A seventh postulated locus, spoIIC, has been recently shown to be the same as spoIID (Lopez-Diaz et al., 1986). Mutations in any of the stage II genetic loci block further steps in sporulation and may also give rise to a variety of bizarre cell forms.

Methods have been described (Errington, 1986) for fusing the $\beta$-galactosidase gene, lacZ, of Escherichia coli into sporulation operons so that enzyme production is determined either by the transcriptional or by the translational control system of the sporulation operon. The fused product can be inserted into a variety of genetic backgrounds by transformation, and production of the enzyme can then be measured either in $\mathrm{Spo}^{+}$strains or in strains carrying a mutation in any one of a number of different sporulation operons.

The experiments described here were intended to obtain at least partial answers to the following questions. (a) At what time is the spoIID operon turned on? (b) Which sporulation operons determine whether or not spoIID will be expressed? (c) Is there an appreciable time lag between the time the message appears and the time at which it is translated? If there were such a gap, translational control would enter as an additional regulatory factor in sporulation. It was for this reason that both transcriptional and translational lac $Z$ fusion plasmids were constructed.

\section{METHODS}

Bacterial strains, phages and plasmids. These are listed in Table 1.

Buffers, chemicals and solutions. The ligation buffer was $66 \mathrm{mM}-\mathrm{Tris} / \mathrm{HCl}(\mathrm{pH} 7 \cdot 2), 5 \mathrm{mM}-\mathrm{MgCl}_{2}, 5 \mathrm{mM}-\mathrm{DTT}$, $1 \mathrm{mM}-\mathrm{ATP}$. Tris buffer was $50 \mathrm{~mm}$-Tris/ $\mathrm{HCl}\left(\mathrm{pH} \mathrm{7.5)}\right.$. $\mathrm{Z}$ buffer $(\mathrm{pH} \mathrm{8})$ contained $\mathrm{Na}_{2} \mathrm{HPO}_{4} .7 \mathrm{H}_{2} \mathrm{O}(60 \mathrm{mM})$, $\mathrm{NaH}_{2} \mathrm{PO}_{4} \cdot \mathrm{H}_{2} \mathrm{O}(40 \mathrm{mM}), \mathrm{KCl}(10 \mathrm{mM}), \mathrm{MgSO}_{4} \cdot 7 \mathrm{H}_{2} \mathrm{O}(1 \mathrm{mM}), 2$-mercaptoethanol $(50 \mathrm{mM})$. RE buffer contained Tris/HCl (50 mM, pH 7.6), $\mathrm{KCl}(50 \mathrm{mM}), \mathrm{MgCl}_{2}$ (10 mM), DTT (10 mM). MUG is 4-methylumbelliferyl- $\beta$-D-

† Present address: Dept. de Genetica, Univ. Autonoma de Barcelona, Bellaterra - Barcelona, Spain. 
Table 1. Plasmids, bacteriophages and bacterial strains

Relevant properties

Plasmid

pSG28

pSG23

pSGLD1

pSGLD4

pSGLD8

Phage $\phi 105 \mathrm{LD} 2$

B. subtilis

Spo ${ }^{+}$strains

MB75

SG46

SG47

Spo $^{-}$strains ${ }^{*}$

43.2

488.1

485.1

46

87.2

69.1

131.3

96

55.2

35.2

26.2

590

133.1

498.2

5

25.5

89.9

156.2

153
Transcriptional lac fusion vector

Translational lac fusion vector pUC13 + $4 \mathrm{kbp}$ EcoRI spoIID locus

$1.1 \mathrm{kbp} H$ indIII fragment in pSGMU2 $0.6 \mathrm{kbp}$ AvaI-HindIII in pSGMU2

spoIID ${ }^{+}, 2 \mathrm{kbp} M b o \mathrm{I}$ insert in $\phi 105 \mathrm{~J} 9$

Genotype

$\operatorname{trp} C 2$

lys-1 metC3 tal-1

lys-1 metC3 tal-1 spoIID: :lacZ-cat

lys-1 metC3 tal-1 spoIID: :lacZ-cat

spo0A43 leu-8

spo0B136 lys -1

spo0G485 lys-1

spo0H46 trpC2

spo0J87 leu-8

spoIIA69 trpC2

spoIIB131 metC3

spoIIF96 trpC2

spoIIG55 trpC2

spoIIIA35 metC3 tal-1 rif-2

spoIIIA26 leu-8 tal-1

spoIIIF 590 lys-I

spoIVC133 trpC2

spoIVE498 trpC2

spoIVG5 trpC2

spoIVG25 trpC2

spoVA89 lys-I

spoVD156 trpC2

spoVE153 trpC2
Source

Errington (1986)

Lopez-Diaz et al. (1986)

Lopez-Diaz et al. (1986)

Source

Laboratory stock

This paper

NG6.21; Piggot (1973)

spo0B136; Hoch \& Mathews (1973)

14UL; Ionesco et al. (1970)

NG7.17; Piggot (1973)

Hranueli et al. (1974)

NG18.6; Piggot (1973)

Z3; Coote (1972a)

Hranueli et al. (1974)

NG12.12; Piggot (1973)

NG1.13; Piggot (1973)

E34; Waites et al. (1970)

Lamont \& Mandelstam (1984)

Z7; Coote (1972b)

IIT; Ionesco et al. (1970)

A8; Waites et al. (1970)

E33; Waites et al. (1970)

Hranueli et al. (1974)

W10; Coote (1972a)

W5; Coote (1972a)

* Other sporulation mutants used were those listed by Errington \& Mandelstam (1986a).

galactoside (Sigma). MU is 4-methylumbelliferone (Sigma). Chase solution was a mixture containing the four deoxyribonucleoside triphosphates (each at $0.5 \mathrm{mM}$ ). 'Klenow fragment' (Amersham) is the large fragment of $E$. coli DNA polymerase 1.

Restriction endonuclease digestions. Restriction enzymes were obtained from Amersham or BRL and used as recommended by the suppliers.

Preparation of DNA. Plasmid DNA was extracted from $E$. coli by the alkaline lysis method (Maniatis et al., 1982). If, after digestion with restriction endonuclease, the sticky ends were to be filled in, the DNA was phenolextracted and precipitated in ethanol as described by Errington (1984). It was then resuspended to a volume of $30 \mu \mathrm{l}$ in RE buffer, $4 \mu \mathrm{l}$ chase solution, 0.5 units of 'Klenow fragment' and $\mathrm{H}_{2} \mathrm{O}$. After incubation for $10 \mathrm{~min}$ at room temperature, the Klenow polymerase was destroyed by heating the mixture at $70^{\circ} \mathrm{C}$ for $10 \mathrm{~min}$. When a DNA fragment was to be recovered from agarose gels, low melting point agarose (BRL) was used and the DNA was extracted by the method of Savva \& Mandelstam (1984).

Chromosomal DNA for transformations was prepared according to Ward \& Zahler (1973).

Growth of bacteria and induction of sporulation. Cells were grown at $37^{\circ} \mathrm{C}$ in casein hydrolysate medium and induced to sporulate in minimal sporulation medium as described by Sterlini \& Mandelstam (1969). The time at which cells were resuspended in sporulation medium is referred to as $t_{0}$ and hourly intervals thereafter as $t_{1}, t_{2}$, etc. The density of cultures at $t_{0}$ was approximately $0.24 \mathrm{mg}$ dry weight per ml.

Transformation and selection of recombinants. B. subtilis recipient cells were made competent and transformed as described by Jenkinson (1983). Selection for chloramphenicol resistance was made on nutrient agar (Oxoid) containing chloramphenicol $\left(5 \mu \mathrm{g} \mathrm{m}^{-1}\right)$ and MUG $\left(50 \mu \mathrm{g} \mathrm{ml}^{-1}\right)$, which allowed recognition of Lac ${ }^{+}$colonies. 
Transductions and infection with phage $\phi 105$. Transduction to $\mathrm{Spo}^{+}$and selection of transductants were as described previously (Lopez-Diaz et al., 1986). Alternatively, a lawn of recipient cells was spread on a nutrient agar plate and drops $(5 \mu l)$ of phage lysate were spotted onto the lawn. Phage infection produced clearly visible lysis and surviving cells were streaked from the centre of plaques and tested for immunity to phage $\phi 105$.

Measurement of $\beta$-galactosidase activity. This was done as described by Errington \& Mandelstam (1986 $a$ ) except that culture samples were $1 \mathrm{ml}$ instead of $0.5 \mathrm{ml}$ and $\mathrm{Z}$ buffer was adjusted to $\mathrm{pH} 8$ instead of $\mathrm{pH} 7$.

Construction of B. subtilis strains SG46 and SG47. For the construction of strain SG46, plasmid pSG28 was digested with $S m a I$ and $B g l \mathrm{II}$ and the $4.8 \mathrm{kbp}$ lacZ-cat fragment was recovered from a low melting point gel, plasmid pSGLD4 was opened with BamHI, and plasmid pSGLD1 was digested with AvaI and the ends filled in. Equimolar amounts of the three pieces of DNA, to give a total of approximately $3 \mu \mathrm{g}$, were ligated together and used to transform strain MB75 to chloramphenicol resistance. Strain SG47 was made in a similar way using plasmid pSG23 cut with SmaI and BgIII, pSGLD4 opened with BamHI, and pSGLD8 cut with HindIII and the ends filled in. In each case a $\mathrm{Cm}^{\mathrm{R}} \mathrm{Spo}^{-} \mathrm{Lac}^{+}$recombinant colony of $\mathrm{MB} 75$ was isolated and purified. The Spo ${ }^{+}$lac fusion strains were made by transducing the $\mathrm{Spo}^{-}$strains to $\mathrm{Spo}^{+}$with phage $\phi 105 \mathrm{LD} 2$, a recombinant phage containing the spoIID locus (Lopez-Diaz et al., 1986).

\section{RESULTS}

\section{Construction of the transcriptional lac fusion}

The transcriptional lac fusion vector plasmid pSG28 (Errington, 1986) contains a $4.8 \mathrm{kbp}$ lac $Z$-cat fragment flanked on both sides by useful restriction sites which allow the lac $Z$ gene to be removed without a promoter but with appropriate $B$. subtilis translation signals. To construct a spoIID : : lacZ fusion, plasmid pSG28 was digested with $S m a I$ and $B g l \mathrm{II}$, and the $4.8 \mathrm{kbp} l a c Z$ cat fragment was recovered from a low melting point agarose gel. This DNA was then ligated to fragments of the spoIID transcriptional unit so that the lac $Z$-cat fragment would be flanked by two regions of the spoIID locus, one of which is known to contain the spoIID promoter. The details of the construction are given below, and are shown in Fig. 1.

Lopez-Diaz et al. (1986) described the construction of several plasmids containing fragments of the spoIID region. One of these, plasmid pSGLD1, a derivative of plasmid pUC13, contains the entire spoIID transcriptional region in an EcoRI fragment. Plasmid pSGLDI was cut with $A v a I$ and the 'sticky' ends were filled in using 'Klenow' polymerase. Previous results using integrational plasmids (Lopez-Diaz et al., 1986) showed that AvaI would separate the spoIID promoter region from the translated region. $A v a I$ would also cut at the $S m a I$ site in the polylinker of pUC13 - thus two blunt ended fragments would be produced (Fig. 1). Plasmid pSGLD4, an integrational plasmid carrying $\mathrm{Cm}^{\mathrm{R}}$ and which contains the end of the spoIID transcriptional unit (Lopez-Diaz et al., 1986), was opened with BamHI (at a site in the polylinker of the original integrational plasmid vector) to provide the second spoIID flanking region.

The two opened plasmids and the lac $Z$-cat fragment were ligated together (a total of about $3 \mu \mathrm{g}$ DNA) and used to transform B. subtilis MB75, which was then plated on agar containing chloramphenicol. Typically, only about $20 \mathrm{Cm}^{\mathrm{R}}$ colonies were obtained. The desired $\mathrm{Cm}^{\mathrm{R}}$ colonies result from ligation of the fragments shown in Fig. 1, followed by recombination between both flanking fragments and the $B$. subtilis chromosome to insert the lac $Z$-cat fragment into the spoIID locus. Some of the $\mathrm{Cm}^{\mathrm{R}}$ colonies could have resulted from self-ligation of the $\mathrm{Cm}^{\mathrm{R}}$ plasmid pSGLD4 followed by integration into the chromosome. However, as shown in previous work (Lopez-Diaz et al., 1986), such integrations yield only $\mathrm{Spo}^{+} \mathrm{Cm}^{\mathrm{R}}$ colonies, since pSGLD4 contains the end of the spoIID transcription unit. About $20 \%$ of transformants were $\mathrm{Spo}^{+}$.

$\mathrm{A} \mathrm{Cm}^{\mathrm{R}} \mathrm{Spo}^{-} \mathrm{Lac}^{+}$colony was selected, purified and named SG46. This strain was found to be stable, i.e. no $\mathrm{Spo}^{+}$or $\mathrm{Cm}^{\mathrm{s}}$ segregants were detected. Donor DNA from strain SG46 was able to transform recipient strain $\mathrm{MB} 75$ to $\mathrm{Cm}^{\mathrm{R}}$ and all $\mathrm{Cm}^{\mathrm{R}}$ transformants were $\mathrm{Spo}^{-}$and $\mathrm{Lac}^{+}$. The $\mathrm{Spo}^{-}$phenotype of the donor and recipient strains was complemented by the recombinant phage $\phi 105 \mathrm{LD} 2$, which contains the spoIID locus (Lopez-Diaz et al., 1986).

\section{Construction of the translational lac fusion}

The translational lac fusion plasmid pSG23 (Errington, 1986) contains a $4.8 \mathrm{kbp}$ lacZcat region with a series of restriction enzyme sites inserted three codons after the start of the lac $Z$ 


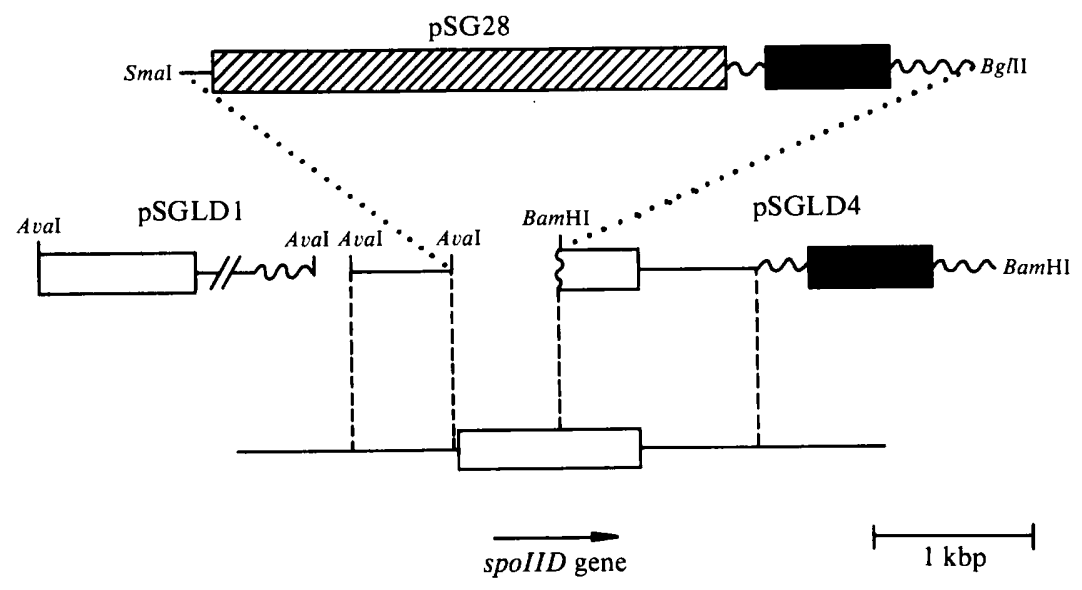

Fig. 1. Schematic representation of the method used to construct the transcriptional lac fusion strain SG46 by insertion of the lacZ-cat fragment from plasmid pSG28 (Errington, 1986) into the spoIID gene. Plasmids pSGLD1 and pSGLD4, which contain fragments of the spoIID region (Lopez-Diaz et al., 1986), and pSG28 containing the lacZ-cat fragment were digested with restriction enzymes as shown. The AvaI sticky ends were filled in and the fragments were ligated together. The ligated DNA was used to transform strain MB75 and chloramphenicol resistant colonies were selected. Those which were also $\mathrm{Spo}^{-}$and $\mathrm{Lac}^{+}$were picked. $\cdots . .$. , In vitro ligation; --.-, the extent of the homologous regions where crossover can occur; - , B. subtilis chromosomal DNA; mm, plasmid DNA; ZZ, lacZ gene; $\square$, cat gene; $\square$, spoIID gene.

gene. Thus the lacZ-cat region could be recovered, without its own transcription and translation signals, and ligated in frame to spoIID fragments so that $\beta$-galactosidase would be synthesized under the transcriptional and translational control of spoIID.

The construction of the spoIID translational lac fusion strain is outlined in Fig. 2. The lac fusion vector plasmid pSG23 was digested with $S m a I$ and $B g / I I$ to release the lacZ-cat fragment. The sequence of the spoIID gene (Lopez-Diaz et al., 1986) showed that the HindIII site in the AvaI-HindIII fragment of plasmid pSGLD8 should, after filling in, give an in-frame fusion when ligated to the lacZ gene. Therefore, plasmid pSGLD8 was opened with HindIII and the ends were filled in. Plasmid pSGLD4 was opened with BamHI to provide the second spoIID fragment. The three were ligated together; the DNA mixture was used to transform MB75, and $\mathrm{Cm}^{\mathrm{R}}$ transformants were selected. $\mathrm{Cm}^{\mathrm{R}}$ transformants were expected to arise as a result of three different mechanisms: (1) by insertion of the spoIID : :lac $Z$ fusion into the chromosome (as shown in Fig. 2) by recombination with the homologous regions flanking the lac Z-cat fragment; (2) by integration of circular structures containing spoIID : : lac fusions into the chromosome by a single crossover Campbell mechanism; (3) by integration of recircularized plasmids pSGLD8 or pSGLD4. Although $\mathrm{Cm}^{\mathrm{R}}$ transformants of the $\mathrm{Spo}^{-}$phenotype could result from any of these three mechanisms, only the first and the second would give a $\mathrm{Lac}^{+}$phenotype. However, only transformants resulting from the first mechanism would be stable, since transformants arising from a single crossover would contain a duplication in the spoIID locus. This duplication would be expected to result in the segregation of $\mathrm{Cm}^{\mathrm{S}} \mathrm{Spo}^{+} \mathrm{Lac}^{-}$colonies under non-selective conditions when recombination between the duplicated regions eliminated the plasmid (Ferrari et al., 1983).

A stable $\mathrm{Cm}^{\mathrm{R}} \mathrm{Spo}^{-} \mathrm{Lac}^{+}$transformant was isolated and named SG47. The $\mathrm{Spo}^{-}$phenotype was complemented by phage $\phi 105 \mathrm{LD} 2$, indicating that the property is a result of the inactivation of the spoIID gene. DNA from SG47 was able to transform MB75 to $\mathrm{Cm}^{\mathrm{R}}$; all resistant colonies were $\mathrm{Spo}^{-}$and $\mathrm{Lac}^{+}$. 


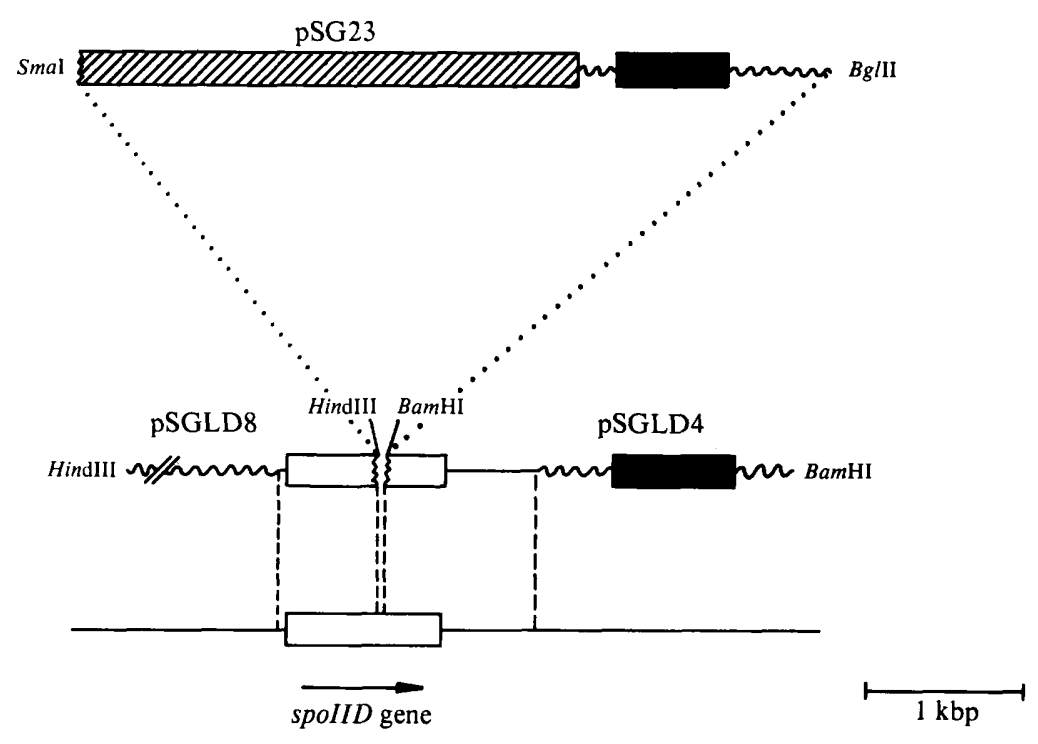

Fig. 2. Schematic representation of the method used to construct the translational lac fusion strain SG47 by insertion of the lac $Z$-cat fragment from the translational fusion vector plasmid pSG23 (Errington, 1986) into the spoIID gene. Plasmids pSGLD8 and pSGLD4 which contain fragments of the spoIID region (Lopez-Diaz et al., 1986), and the fusion plasmid pSG23 were digested with restriction enzymes as shown. The HindIII sticky ends were filled in and the fragments were ligated together and used to transform strain MB75. Chloramphenicol resistant colonies were selected and those which were $\mathrm{Spo}^{-}$and $\mathrm{Lac}^{+}$were picked. The symbols are defined in Fig. 1 .

\section{Measurement of $\beta$-galactosidase activity under sporulation conditions}

The lac fusion strains SG46 and SG47 were transduced with phage $\phi 105 \mathrm{LD} 2$ in order to complement the disrupted spoIID gene and make the strains $\mathrm{Spo}^{+}$. The activity of $\beta$ galactosidase was then measured in these $\mathrm{Spo}^{+}$strains at $t_{0}$ and at $30 \mathrm{~min}$ intervals after the induction of sporulation. The results are shown in Fig. 3. $\beta$-Galactosidase starts to be synthesized at about $t_{1.5}$ and reaches its maximum at $t_{2}-t_{2.5}$. The same pattern was present in both transcriptional and translational fusion strains.

\section{Effect of sporulation mutations on the expression of spolID}

The spoIID translational lac fusion was transferred to the chromosome of a range of sporulation mutants in the following way. DNA from strain SG47 was used to transform competent cells of each mutant and $\mathrm{Cm}^{\mathrm{R}}$ transformants were selected. These transformants would be double mutants in that they would now carry a disrupted spoIID gene as well as the original lesion. The spoIID mutation in each was then complemented by infecting the cells with recombinant phage $\phi 105 \mathrm{LD} 2$, which carries the spoIID locus. Each infected strain was tested for immunity to $\phi 105$ (see Methods) and microscopically for the restoration of the original Spo phenotype in the case of those mutants blocked at later stages, i.e. stage III onwards. $\beta$ Galactosidase production was then measured at $t_{0}$ and at hourly intervals to $t_{4}$ or $t_{5}$. In each experiment $B$. subtilis strains 168 and SG47 were used as negative and positive controls respectively. The results are shown in Table 2 . No $\beta$-galactosidase activity was found in any stage 0 mutants or in any stage II mutants except spoIIB and spoIIF. $\beta$-Galactosidase was produced in all stage III, IV, and V mutants tested.

\section{DISCUSSION}

From work done in various laboratories in the past few years it is now apparent that most if not all of the sporulation operons controlling stage $0-\mathrm{I}$ of sporulation are expressed during 


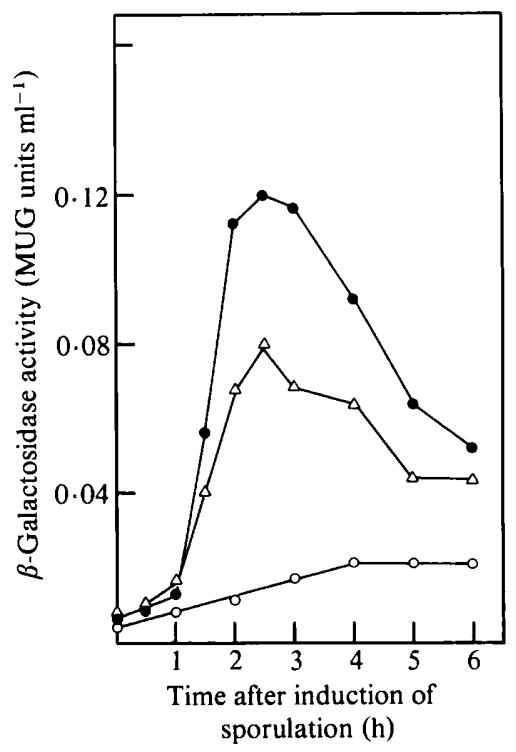

Fig. 3. $\beta$-Galactosidase activity in the spoIID transcriptional fusion strain SG46 and the translational fusion strain SG47. Both strains were transduced with $\phi 105 \mathrm{LD} 2$ (which contains the spoIID gene) to complement the disrupted gene in the fusion strains and make them $\mathrm{Spo}^{+}$. Samples $(1 \mathrm{ml})$ were taken hourly, incubated with MUG and the fluorescent product measured against standards (see Methods). -, SG46, the transcriptional lac fusion strain; $\triangle$, SG47, the translational lac fusion strain; $O, B$. subtilis 168 without a lac $Z$ gene, showing a spurious low-level background activity.

\section{Table 2. Expression of the spoIID operon in different mutants}

The lac $Z$ gene was transferred to strains harbouring defects in spo loci by transformation with DNA from strain SG47. The spoIID mutation in each was then complemented by infecting with the recombinant phage $\phi 105 \mathrm{LD} 2$. The resulting strains were grown up, transferred to sporulation medium and the cultures sampled at hourly intervals for the measurement of $\beta$-galactosidase. Peak activity was generally found at $t_{2}$, unless indicated otherwise. + , Activity roughly equal to that of the wild-type; -, activity about the same as the background activity of $B$. subtilis containing no lac $Z$ gene (see Fig. 3); $+^{*}$, about $50 \%$ of the activity of the wild-type; $+^{* *}$, about $50 \%$ activity but delayed by about $1 \mathrm{~h}$.

\begin{tabular}{cccccccc} 
& \multicolumn{7}{c}{} \\
\cline { 2 - 7 } Mutated locus & $0-I$ & $I I$ & $I I I$ & $I V$ & $V$ & $V I$ & ger \\
$A$ & - & - & + & + & + & $+^{*}$ & \\
$B$ & - & + & $+^{*}$ & + & + & & \\
$C$ & & & $+^{* *}$ & + & + & + & \\
$D$ & - & & + & + & + & & + \\
$E$ & - & - & $+^{*}$ & + & + & & + \\
$F$ & - & + & $+^{* *}$ & + & + & & \\
$G$ & - & - & & $+^{*}$ & + & & \\
$H$ & - & & & & + & & \\
$J$ & - & & & & + & & \\
$K$ & - & & & & & &
\end{tabular}

vegetative growth. It has also long been known that mutations in some of the stage 0-I genes affect not only the ability to sporulate but also competence in genetic transformation, the response to infection by various types of bacteriophage, etc. In the light of this information it seems reasonable to exclude the stage $0-I$ operons from the sequence of events that is set in train when sporulation is initiated by subjecting cells of $B$. subtilis to conditions of nutritional 'stepdown'. 
On the basis of this view, sporulation as a developmental process can be considered to begin with stage II, i.e. with the laying down of a membrane septum asymmetrically to give two unequal compartments, the smaller of which is then engulfed by the larger and develops into a spore. The events from the formation of the septum to the engulfment are known to be specifically controlled by six operons (see Introduction) although it is possible that one or more operons still remain to be discovered.

Two questions posed in the Introduction are answered by the results illustrated in Fig. 3. It is apparent that the curves for transcription and translation both rise sharply at about $t_{2}$ and, within the accuracy of the method, there is no delay between them. Clearly this does not rule out translational control, but it does mean that it is a factor that need not be taken into consideration. Incidentally, results obtained for the spoVA operon (Savva \& Mandelstam, 1985; Errington \& Mandelstam, 1986 b) indicate that there is no translational delay in its expression; by the time the message becomes measurable by Northern blot hybridization, its translation is already detectable by the more sensitive lac $Z$ fusion technique. By contrast, kinetic measurements on the rate of disappearance of the enzyme suggest the possibility that there may, indeed, be a translational control factor (Errington \& Mandelstam, 1986a).

It is apparent (see Table 2) that spoIID is not expressed in any strains carrying mutations in stage 0 operons. This merely confirms the point, made in the Introduction, that expression of the spo0 genes during vegetative growth is a prerequisite for initiating sporulation.

spoIID failed to be expressed in strains that were damaged in spoIIA, spoIIE and spoIIG. The expression of these three loci can, therefore, be reasonably assumed to precede that of spoIID. It is known that the expression of spoIIA is not dependent on the intactness of any of the other loci governing stage II (Errington \& Mandelstam, 1986a). This finding could by itself be interpreted in either of two ways: firstly that spoIIA is the earliest of the known stage II operons to be expressed, or alternatively that it is expressed in parallel with one or more stage II operons. With spoIIE and spoIIG we have, however, the additional information that spoIIG is not expressed in spoIIA mutants (Trempy et al., 1985a). We also known that spoIIG codes for a pre-sigma factor $\left(M_{\mathrm{r}} 31000\right.$ ), which may then be processed by spoIIE to give the sigma factor $\sigma^{29}$ (Trempy et al., $1985 \mathrm{~b}$ ). These facts would place spoIIA earlier in a linear sequence than either of the other two operons. We have no information at present that allows us to determine whether spoIIE and spoIIG are expressed together or in sequence. In the scheme given below they are therefore bracketed together.

The results of the present paper make it apparent that expression of spoIID follows that of the other three loci. Two others remain to be considered, spoIIB and spoIIF. According to the data of Table 2, these are clearly later in stage II than any of the others we have considered, and the provisional order of expression is therefore as follows: spoIIA $\rightarrow[$ spoIIG, spoIIE] $\rightarrow[$ spoIID, spoIIB, spoIIF].

Clearly the construction of further lac $Z$ fusions can be expected to give an unequivocal order of expression of the loci controlling stage II of sporulation.

We thank Dr J. Errington for supplying us with the lac fusion vector plasmids and for advice on their use. We gratefully acknowledge the work of Gill Roberts in constructing many of the isogenic strains of the sporulation mutants. This work was supported by grants from the Science and Engineering Research Council and Fundacion Juan March (Spain).

\section{REFERENCES}

COOTE, J. G. (1972a). Sporulation in Bacillus subtilis. Characterization of oligosporogenous mutants and comparison of their phenotypes with those of asporogenous mutants. Journal of General Microbiology 71, 1-15.

COOTE, J. G. (1972b). Sporulation in Bacillus subtilis. Genetic analysis of oligosporogenous mutants. Journal of General Microbiology 71, 17-27.

ERRINGTON, J. (1984). Efficient Bacillus subtilis cloning system using bacteriophage vector $\phi 105 \mathrm{~J} 9$. Journal of General Microbiology 130, 2615-2628.

ERRINGTON, J. (1986). A general method for fusion of the Escherichia coli lacZ gene to chromosomal genes in Bacillus subtilis. Journal of General Microbiology 132, 2953-2966.

ERrington, J. \& MANDElstam, J. (1986a). Use of a lac $Z$ gene fusion to determine the dependence pattern of sporulation operon spoIIA in spo mutants 
of Bacillus subtilis. Journal of General Microbiology 132, 2967-2976.

ERrington, J. \& Mandelstam, J. (1986b). Use of a lac $Z$ gene fusion to determine the dependence pattern and the spore compartment expression of sporulation operon spoVA in spo mutants of Bacillus subtilis. Journal of General Microbiology 132, 29772985.

Ferrari, F. A., Nguyen, A., Lang, D. \& Hoch, J. A. (1983). Construction and properties of an integrable plasmid for Bacillus subtilis. Journal of Bacteriology 154, 1513-1515.

Hoch, J. A. \& Mathews, J. L. (1973). Chromosomal location of pleiotropic negative sporulation mutations in Bacillus subtilis. Genetics 73, 215-228.

Hranueli, D., Piggot, P. J. \& Mandelstam, J. (1974). Statistical estimate of the total number of operons specific for Bacillus subtilis sporulation. Journal of Bacteriology 119, 684-690.

Ionesco, H., Michel, J., Cami, B. \& Schaeffer, P. (1970). Genetics of sporulation in Bacillus subtilis Marburg. Journal of Applied Bacteriology 33, 13-24.

JENKINSON, H. F. (1983). Altered arrangement of proteins in the spore coat of a germination mutant of Bacillus subtilis. Journal of General Microbiology 129, 1945-1958.

LAMONT, I. L. \& MANDELSTAM, J. (1984). Identification of a new sporulation locus, spoIIIF, in Bacillus subtilis. Journal of General Microbiology 130, 12531261.

Lopez-Diaz, I., Clarke, S. \& Mandelstam, J. (1986). spoIID operon of Bacillus subtilis: cloning and sequence. Journal of General Microbiology 132, 341-354.

Maniatis, T., Fritsch, E. F. \& SambrooK, J. (1982), Molecular Cloning: a Laboratory Manual. Cold Spring Harbor, NY: Cold Spring Harbor Laboratory.
Piggot, P. J. (1973). Mapping of asporogenous mutations of Bacillus subtilis: a minimum estimate of the number of sporulation operons. Journal of Bacteriology 114, 1241-1253.

Savva, D. \& Mandelstam, J. (1984). Cloning of the Bacillus subtilis spollA and spoVA genes in phage $\phi 105 \mathrm{DI}$ : 1t. Journal of General Microbiology 130, 2137-2145.

Savva, D. \& Mandelstam, J. (1985). Use of cloned spoIIA and spoVA probes to study synthesis of mRNA in wild-type and asporogenous mutants of Bacillus subtilis. In Molecular Biology of Microbial Differentiation, pp. 55-59. Edited by P. Setlow \& J. Hoch. Washington, DC: American Society for Microbiology.

Sterlini, J. M. \& Mandelstam, J. (1969). Commitment to sporulation in Bacillus subtilis and its relationship to the development of actinomycin resistance. Biochemical Journal 113, 29-37.

Trempy, J. E., Morrison-Plummer, J. \& HaldenWANG, W. G. (1985a). Synthesis of $\sigma^{29}$, an RNA polymerase specificity determinant, is a developmentally regulated event in Bacillus subtilis. Journal of Bacteriology 161, 340-346.

TRempy, J. E., Bonamy, C., Szulmajster, J. \& Haldenwang, W. G. (1985b). Bacillus subtilis sigma factor $\sigma^{29}$ is the product of the sporulation-essential gene spoIIG. Proceedings of the National Academy of Sciences of the United States of America 82, 41894192.

WaItes, W. M., Kay, D., DaWes, I. W., WoOd, D. A., Warren, S. C. \& Mandelstam, J. (1970). Sporulation in Bacillus subtilis: correlation of biochemical events with morphological changes in asporogenous mutants. Biochemical Journal 118, 667-676.

WARD, J. B., JR \& Zahler, S. A. (1973). Genetic studies of leucine biosynthesis in Bacillus subtilis. Journal of Bacteriology 116, 719-726. 